\title{
Nursing Students' Perception, Anxiety, and Stress during Objective Structured Clinical Examination (OSCE)
}

\author{
Eman S Ahmed, Safaa A., Mohamed, Mogedda M. Mehany \& Youssria E. Yousef. \\ Assistant Professor Pediatric Nursing, Faculty of Nursing, Assiut University, Egypt. \\ Assistant Professor. Community Health Nursing, Faculty of Nursing, Assiut University, Egypt. \\ Lecturer of Critical Care Nursing, Faculty of Nursing, Assiut University, Egypt. \\ Lecturer o f Pediatric Nursing, Faculty of Nursing, Sohag University, Egypt.
}

\begin{abstract}
Determining the quality of students learning is an ongoing challenge to all nursing students. Aim: The aim of this study was to assess students' perception, stress, and anxiety experienced by nursing students during OSCE, for the $1^{\text {st }}$ and $4^{\text {th }}$ year nursing students. Method: - A descriptive exploratory research design was used for this study. This study was conducted at Faculty of Nursing, Assiut University, Egypt. A total of 451 undergraduate nursing students were enrolled in this study. First year $(n=312)$ and $4^{\text {th }}$ year $(n=139)$. Three tools were used to collect data in this study: Tool one: OSCE questionnaire sheet to test perception of the nursing students during OSCE. Tool two: perceived stress scale (PSC) and Tool three: State and Trait Anxiety Inventory. Results: There was agreement among students that exam were fair, covered a wide area of knowledge, but needs more time each station. No significant differences between $1^{\text {st }}$ and $4^{\text {th }}$ year nursing students were found regarding the level of stress and anxiety. There was significant negative correlation between anxiety state, total anxiety, and stress with nearly most of OSCE attributes. Conclusion: nursing students viewed OSCE as an objective assessment for nursing practical courses. It covered a wide range of knowledge; the majority of the students viewed the examination as fair.
\end{abstract}

\section{Key Words: OSCE, Perception, Stress, Anxiety \& Nursing Students.}

\section{Introduction}

Objective structure clinical examination (OSCE) in nursing students is a major challenge for nurse educators (Walsh et al., 2009). Limited sites for clinical placements and varying clinical hour requirements, students may not have sufficient opportunities to integrate classroom content into clinical performance (Benner, et al., 2010). Since the development of OSCE in the (1970s by Dr. Ronald Harden), it has gained acceptance as a benchmark for clinical skills assessment (Bartfay et al., 2004). OSCE is designed to assess a range of professional skills and knowledge involved in the clinical practice, and defined as "an approach to assess clinical competence in which the components of competence are assessed in a well-planned or structured way with attention being paid to objectivity".

Objective Structured Clinical Examination is also increasingly being adapted for use in various health professional programs, commonly nursing and allied health, with many of the variants focusing on integrated, rather than isolated, assessment tasks which are considered to more accurately reflect reallife clinical settings (Major, 2005). As reported by Mitchell et al., (2009): "An OSCE requires each student to demonstrate specific skills and behaviors in a simulated work environment with standardized patients. It typically consists of a series of short assessment tasks (stations), each of which is assessed by an examiner using a predetermined, objective marking scheme (Bartfay et al., 2004, Major, 2005, Ward \& Barratt, 2005). It is increasingly being used as a method of assessment in nursing and allied health curricula (Bartfay et al., 2004; Wessel et al., 2003)."

It is evident that a wide range of evaluation methods are necessary to assess student nurses' clinical competence and greater emphasis should be placed on those methods which encourage the learning of clinical skills and concurrently provide an appropriate mechanism for assessing them. The Objective Structured Clinical Examination (OSCE) is widely used to assess the clinical competence. (Khattab \& Rawlings, 2001 \& Panzarella \& Manyon, 2007). The OSCE process has been adapted to test the trainees from different healthcare related discipline. In nursing education principles of OSCE can also be used in a formative way to enhance acquisition through simulation( Alinier, 2009). The examination involves using simulated clinical situations as a tool in conducting a summative evaluation of trainee competence (Miller, 2009). It was created to enable better assessment and quantification of clinical skills acquisition by students. (Bensenor, 2004). OSCE stations may be interactive or non-interactive, a student in an interactive station is observed and evaluated by a trained examiner using prepared 
checklist. Non-interactive stations involve written answers to specific tasks or problems that do not require a direct observation, and are usually marked after the examination [Austin et al.,2003). It eliminates the luck of the draw, reduces variations in marking standards from examiner to examiner and can accurately reflect the real-life tasks of the nurses).

Changes in the curriculum format can result in anxiety for students as well as for those involved in implementing the changes. When the Faculty does not pay attention to feedback and subtle cues from students, it can sometimes be overlooked that students are experiencing their own stressors (Rosemaire et al., 2002). Many studies on students' preparation and performance on the OSCE have been done, but a few studies address students' perception, anxiety and stress associated with this type of exam.

\section{Significance of the study}

The evidence base for the use of OSCE's is extensive in medicine while that related to nursing is more limited. Rushforth (2007) notes the diversity of different OSCE processes and the need to pilot and ensure accuracy with each new assessment. Rushforth (2007) also considers that nursing has adapted the original Harden model to suit nursing students.

\section{Aim of the study}

The aims of this study were to assess first and fourth year nursing students for:

1-Perception about OSCE exam.

2-Stress associated with OSCE exam.

3-Anxiety during OSCE exam.

4-To compare the perception of stress and anxiety about OSCE exam between first and fourth year nursing students.

Research questions

1-What is the perception of nursing students about OSCE exam?

2-To what degree do students experience stress and /or anxiety associated with OSCE ?

3-Is there a difference between perception, stress, and anxiety of the OSCE among $1^{\text {st }}$ and $4^{\text {th }}$ year nursing students?

\section{Sapject \& method}

Research design: a descriptive exploratory research design was used for this study.

Setting: The study was conducted at Faculty of Nursing, Assiut University, Egypt.

Sample: The study sample involved all first year nursing students $(n=312)$ who agreed to participate in the study and all fourth year nursing students $(\mathrm{n}=$ 139) who were enrolled in Fundamental and community nursing courses, respectively. First and the fourth year nursing students were chosen because it is the first time for first year nursing students to go through OSCE, while fourth-year nursing students had a long experience with OSCE. The total number of nursing students was 451. All of them were females as the Faculty of Nursing; Assiut University has not yet opened for males.

Tools of the study

Three tools were used for data collection in this study Tool one: "OSCE evaluation questionnaire"

This tool was modified by the researcher; it is a selfadministered version of the questionnaire from a study done by Pierre, et al., (2004), it is a standardized, valid and reliable questionnaire. Only 26 items of the scale were used, the modification was done to be suitable for the nursing students. The items of the modified scale were classified into $\mathbf{3}$ sections

1- Evaluation of OSCE that includes 13 items such as fairness of the exam, the area of knowledge covered, time of each station, adequacy of time at each question and the administration and organization of OSCE.

2- The quality of OSCE performance which comprises 9 items such as students' awareness of nature of the exam, sequence of stations, tasks of the exam and structure of the exam.

3- Students' perception of validity and reliability of the OSCE which consists of 4 items such as reality in assessing the course, the objectivity of OSCE exam and standardization of the exam.

Scoring system: A Five-points Likert-type scale that indicates the agreement, from strongly disagree (with a score of 1) to strongly agree scored as 5. The mean score of each item in the questionnaire was calculated. The Higher mean score indicates higher agreements of students.

Tool two: "Perceived Stress Scale (PSC)"

It was developed by Cohen et al. (1983) to indicate the nursing students' stress of the OSCE. It consists of 10 items, as (you should put some examples responses). It recorded on 5 points Likert Scale ranges from never (0) to too much (4), the maximum score was 40 . Higher the score indicates higher stress, some questions such as $(4,5,7$, and 8$)$ need to be reversed.

Tool Three: "State-trait anxiety inventory"

The original scale was initially developed by Spielberger et al., (1973). The Arabic version was translated by El- Beheary, (1998). Which was adopted by the researchers, this scale is composed of two parts:

Part I: measures anxiety traits.

Part II: measures anxiety state.

Each part comprises of 20 statements. This scale is scored on a 4 points Likert scale, with a total score 
ranging from a minimum of 20 grads to a maximum of 80 grades.

Anxiety levels: students who had score ranged from 20 to 39 had mild anxiety, those who had score ranged from 40 to 59 had moderate anxiety, and from 60 to 80 indicated severe anxiety, for each part separately.

\section{Method}

1-An official permission was obtained from the dean of the Faculty of Nursing to collect data from students.

2-Tool one "OSCE evaluation questionnaire" was modified by the researcher from Pierre, et al., to evaluate the OSCE, indicate the quality of OSCE performance, and the students' perception of validity and reliability of the OSCE.

3-Tool two "Perceived Stress Scale (PSC)" was developed by Cohen et al. to indicate the nursing students' stress of the OSCE.

4-Tool Three "State-trait anxiety inventory" was initially developed by Spielberger et al., the Arabic version was translated by El- Beheary, 1984. Which was adopted by the researchers, to measure anxiety traits and anxiety state?

5-Content validity for the Arabic version of the questionnaire was obtained by five panels of experts in the field of nursing. Cronbach's Alpha revealed high reliability which is $0.822,0.843$ and 0.853 for tools I, II and tool III, respectively. The study was carried out during the academic year 2011- 2012.

6-A pilot study was done on $5 \%$ of the sample ( 23 students) from first and fourth year to test the clarity of the sheet and to estimate the time needed to fill the sheet. The necessary modifications were done and they were excluded from the study sample.

7-Hence, the structure of OSCE had many stations and a limited time available for each station so, few students were in the lab during the OSCE exam while, the rest of students were waiting in the lecture hall. During the waiting time, a modified Arabic version of the questionnaire was distributed among students to facilitate a better understanding of the questions.

\section{Ethical considerations}

Students were informed about the nature of the study and that their participation is voluntary. The written agreement was obtained from all students who agreed to participate in the study. Confidentiality and anonymity of the collected data were assured. An approval to conduct the study was obtained from the Dean of the Faculty of Nursing and head of Fundamental and Community nursing departments.

\section{Statistics \& data analysis}

Data were coded and analyzed using SPSS version 20. Descriptive analyzes were conducted to determine the frequency distributions of the study variables. Pearson's Product Moment Correlation Coefficients were calculated to assess the relationship among the study variables. Differences between groups were tested using $\mathrm{X}^{2}$ and student t- test. 


\section{Results}

Table (1): Personal characteristics of the studied students $(n=451)$.

\begin{tabular}{|c|c|c|c|c|c|}
\hline \multirow{3}{*}{ Characteristics } & \multicolumn{4}{|c|}{ Academic year } & \multirow{3}{*}{ P-value } \\
\hline & \multicolumn{2}{|c|}{$\begin{array}{c}\text { First year } \\
(n=312)\end{array}$} & \multicolumn{2}{|c|}{$\begin{array}{c}\text { Fourth year } \\
(n=139)\end{array}$} & \\
\hline & No. & $\%$ & No. & $\%$ & \\
\hline \multicolumn{5}{|l|}{ Residence } & \multirow{3}{*}{0.527} \\
\hline Rural & 190 & 60.9 & 89 & 64.0 & \\
\hline Urban & 122 & 39.1 & 50 & 36.0 & \\
\hline \multicolumn{5}{|l|}{ Age } & \multirow{3}{*}{$0.000 *$} \\
\hline Mean \pm SD & \multicolumn{2}{|c|}{$17.94 \pm 0.99$} & \multicolumn{2}{|c|}{$21.04 \pm 0.78$} & \\
\hline Range & \multicolumn{2}{|c|}{$16-21$} & \multicolumn{2}{|c|}{$19-22$} & \\
\hline
\end{tabular}

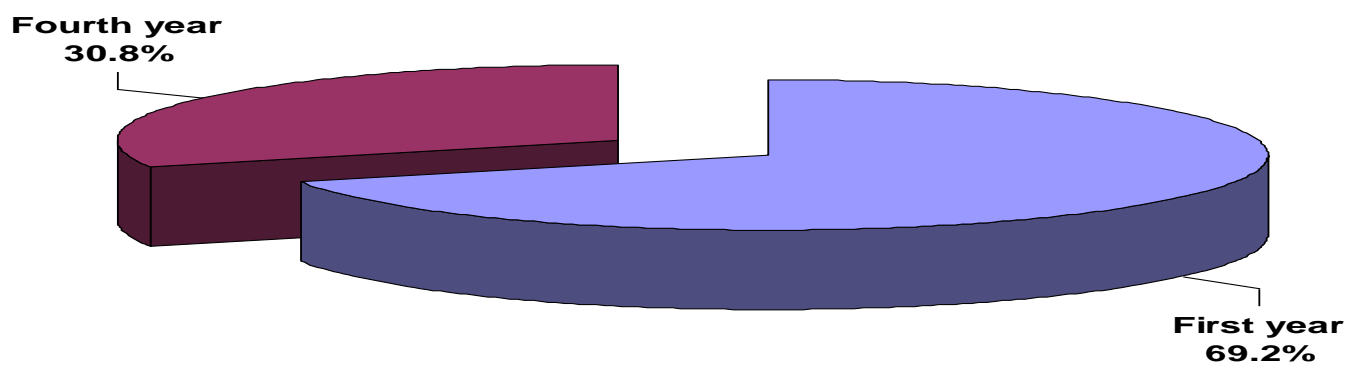

Figure (1): Percentage distribution of students according to their academic years $(n=451)$.

Table(2): Mean scores and standard deviation for nursing students' assessment of OSCE questionnaire items.

\begin{tabular}{|l|c|c|c|}
\hline \multicolumn{1}{|c|}{ Items } & \multicolumn{1}{c|}{ First year } & Fourth year & \multirow{2}{*}{ P-value } \\
\cline { 2 - 4 } & \multicolumn{1}{|c|}{ Mean \pm SD } & Mean \pm SD & \\
\hline The exam was fair & $2.16 \pm 0.92$ & $2.35 \pm 0.76$ & $0.038^{*}$ \\
\hline Wide knowledge area covered & $2.07 \pm 0.93$ & $2.28 \pm 0.99$ & $0.032^{*}$ \\
\hline Needed more time at stations & $3.50 \pm 1.26$ & $3.21 \pm 1.09$ & $0.018^{*}$ \\
\hline Exam well administered & $2.35 \pm 1.19$ & $2.14 \pm 0.83$ & 0.060 \\
\hline Exam very stressful & $1.99 \pm 1.11$ & $1.81 \pm 0.89$ & 0.080 \\
\hline Exam well-structured and sequenced & $2.30 \pm 1.01$ & $2.33 \pm 0.88$ & 0.789 \\
\hline Exam minimized chance of failing & $2.18 \pm 1.00$ & $2.15 \pm 0.91$ & 0.750 \\
\hline Allowed students to compensate in some areas & $2.13 \pm 1.06$ & $2.38 \pm 1.19$ & $0.027^{*}$ \\
\hline Highlightened of weakness & $2.41 \pm 1.10$ & $2.83 \pm 0.80$ & $0.000^{*}$ \\
\hline The time for each question was adequate & $3.53 \pm 1.33$ & $3.79 \pm 1.11$ & $0.043^{*}$ \\
\hline The questions asked were of appropriate level & $2.55 \pm 1.31$ & $2.94 \pm 1.25$ & $0.003^{*}$ \\
\hline Wide range of clinical skills covered & $2.05 \pm 0.97$ & $2.17 \pm 0.92$ & 0.213 \\
\hline Feedback from observer helps me a lot & $2.02 \pm 1.06$ & $1.94 \pm 1.06$ & 0.455 \\
\hline Total mean score (65) & $31.26 \pm 5.51$ & $32.32 \pm 5.33$ & $0.010^{*}$ \\
\hline
\end{tabular}


Table(3): Mean scores and standard deviation of quality of OSCE performance among studied students $(n=451)$.

\begin{tabular}{|l|c|c|c|}
\hline \multicolumn{1}{|c|}{ Items of quality of the OSCE performance } & First year & Fourth year & \multirow{2}{*}{ P-value } \\
\cline { 2 - 4 } & Mean \pm SD & Mean \pm SD & \\
\hline Fully aware of the nature of the exam & $2.49 \pm 1.08$ & $2.28 \pm 0.85$ & $0.040^{*}$ \\
\hline Asks reflected those taught & $2.12 \pm 0.94$ & $1.99 \pm 0.86$ & 0.180 \\
\hline Time at each station was adequate & $3.50 \pm 1.26$ & $3.21 \pm 1.09$ & $0.018^{*}$ \\
\hline Students aware of the level of information needed & $2.12 \pm 0.96$ & $2.19 \pm 0.94$ & 0.460 \\
\hline Instructions were clear and unambiguous & $2.27 \pm 1.22$ & $2.15 \pm 0.92$ & 0.309 \\
\hline Exam provide opportunities to learn & $2.12 \pm 0.96$ & $2.19 \pm 0.94$ & 0.460 \\
\hline Sequence of stations was logical and appropriate & $2.30 \pm 1.01$ & $2.33 \pm 0.88$ & 0.789 \\
\hline OSCE was a practical and useful experience & $2.06 \pm 1.15$ & $2.27 \pm 1.08$ & 0.065 \\
\hline Exam was intimidating & $1.96 \pm 1.25$ & $1.69 \pm 0.95$ & $0.025^{*}$ \\
\hline Total mean score (45) & $20.94 \pm 5.39$ & $20.30 \pm 5.11$ & 0.240 \\
\hline
\end{tabular}

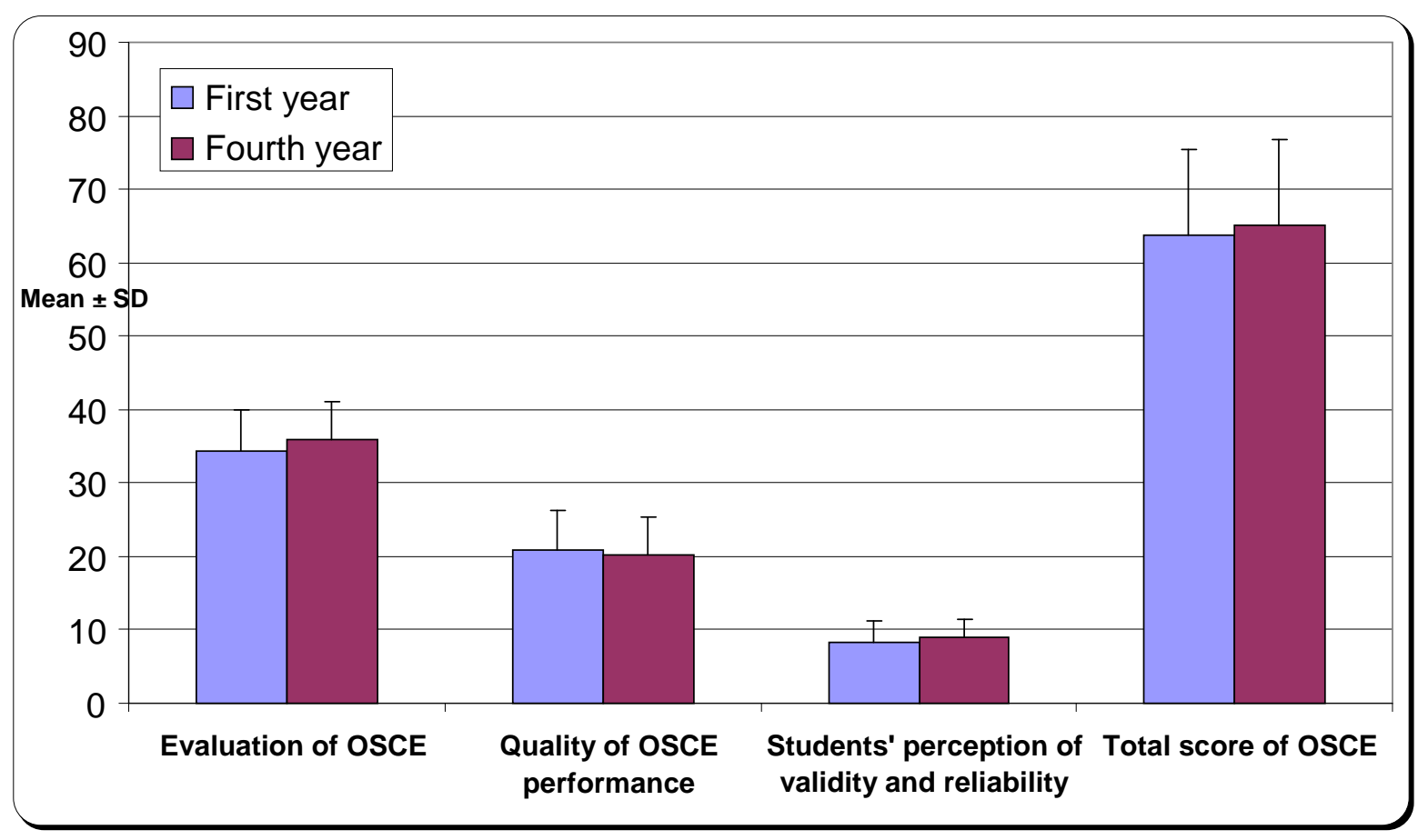

Figure (2): Perception of first and fourth nursing students for OSCE attributes

Table (4): mean scores for students' perception of validity and reliability items.

\begin{tabular}{|l|l|l|l|}
\hline \multicolumn{1}{|c|}{ Items } & First year & Fourth year & \multirow{2}{*}{ P-value } \\
\cline { 2 - 3 } & Mean \pm SD & Mean \pm SD & \\
\hline OSCE provides true measure of essential clinical skills & $2.12 \pm 0.96$ & $2.19 \pm 0.94$ & 0.460 \\
\hline OSCE scores are standardized & $2.06 \pm 0.81$ & $2.19 \pm 0.76$ & 0.129 \\
\hline $\begin{array}{l}\text { It was a realistic assessment for the course (assess what I've } \\
\text { learned) }\end{array}$ & $2.06 \pm 1.15$ & $2.27 \pm 1.08$ & 0.065 \\
\hline Personality and social relations will not affect OSCE scores & $2.16 \pm 0.92$ & $2.35 \pm 0.76$ & $0.038^{*}$ \\
\hline Total mean score (20) & $8.40 \pm 2.82$ & $8.99 \pm 2.38$ & $0.031^{*}$ \\
\hline
\end{tabular}


Table(5): Students' stress mean scores associated with OSCE.

\begin{tabular}{|c|c|c|c|}
\hline \multirow{2}{*}{ Stress Items } & First year & Fourth year & \multirow{2}{*}{ P-value } \\
\hline & Mean \pm SD & Mean \pm SD & \\
\hline \multicolumn{4}{|l|}{ In the last month; } \\
\hline $\begin{array}{l}\text { How often have you been upset because of something that } \\
\text { happened unexpectedly? }\end{array}$ & $2.71 \pm 1.41$ & $2.90 \pm 1.11$ & 0.157 \\
\hline $\begin{array}{l}\text { How often have you felt that you were unable to control the } \\
\text { important things in your life? }\end{array}$ & $3.07 \pm 1.16$ & $2.86 \pm 0.87$ & 0.060 \\
\hline How often have you felt nervous and "stressed"? & $3.22 \pm 1.34$ & $3.10 \pm 1.41$ & 0.386 \\
\hline $\begin{array}{l}\text { How often have you felt confident about your ability to handle } \\
\text { your personal problems? }\end{array}$ & $3.26 \pm 1.09$ & $3.24 \pm 1.09$ & 0.819 \\
\hline How often have you felt that things were going your way? & $3.04 \pm 1.42$ & $3.12 \pm 1.16$ & 0.527 \\
\hline $\begin{array}{l}\text { How often have you found that you could not cope with all the } \\
\text { things that you had to do? }\end{array}$ & $3.17 \pm 1.10$ & $3.05 \pm 0.97$ & 0.283 \\
\hline How often have you been able to control irritations in your life? & $2.83 \pm 1.09$ & $2.71 \pm 1.07$ & 0.260 \\
\hline How often have you felt that you were on top of things? & $2.76 \pm 1.25$ & $2.90 \pm 1.06$ & 0.263 \\
\hline $\begin{array}{l}\text { How often have you been angered because of things that were } \\
\text { outside of your control? }\end{array}$ & $3.12 \pm 1.49$ & $3.56 \pm 1.26$ & $0.002 *$ \\
\hline $\begin{array}{l}\text { How often have you felt difficulties were piling up so high that } \\
\text { you could not overcome them? }\end{array}$ & $3.25 \pm 1.29$ & $3.35 \pm 1.09$ & 0.465 \\
\hline $\begin{array}{l}\text { Total stress score } \\
\end{array}$ & $20.64 \pm 5.82$ & $20.86 \pm 4.23$ & 0.700 \\
\hline
\end{tabular}

Table(6): Percentage distribution of the studied students in relation to the anxiety level.

\begin{tabular}{|c|c|c|c|c|c|}
\hline \multirow{3}{*}{ Anxiety Level } & \multicolumn{4}{|c|}{ Academic year } & \multirow{3}{*}{ P-value } \\
\hline & \multicolumn{2}{|c|}{ First year $(n=312)$} & \multicolumn{2}{|c|}{ Fourth year $(n=139)$} & \\
\hline & No. & $\%$ & No. & $\%$ & \\
\hline \multicolumn{5}{|l|}{ Anxiety trait } & \multirow{4}{*}{0.297} \\
\hline Mild & 18 & 5.8 & 8 & 5.8 & \\
\hline Moderate & 262 & 84.0 & 123 & 88.5 & \\
\hline Severe & 32 & 10.3 & 8 & 5.8 & \\
\hline \multicolumn{5}{|l|}{ Anxiety state } & \multirow{4}{*}{0.805} \\
\hline Mild & 39 & 12.5 & 20 & 14.4 & \\
\hline Moderate & 220 & 70.5 & 94 & 67.6 & \\
\hline Severe & 53 & 17.0 & 25 & 18.0 & \\
\hline \multicolumn{5}{|l|}{ Anxiety total } & \multirow{4}{*}{0.429} \\
\hline Mild & 10 & 3.2 & 3 & 2.2 & \\
\hline Moderate & 264 & 84.6 & 124 & 89.2 & \\
\hline Severe & 38 & 12.2 & 12 & 8.6 & \\
\hline
\end{tabular}

Table(7): Mean score of anxiety and stress among first and fourth year nursing students during OSCE $(\mathrm{n}=451)$

\begin{tabular}{|l|c|c|c|c|}
\hline \multirow{2}{*}{ Anxiety and Stress } & \multirow{2}{*}{ Total score } & First year $(\mathbf{n}=\mathbf{3 1 2})$ & Fourth year $(\mathbf{n}=\mathbf{1 3 9})$ & \multirow{2}{*}{ P-value } \\
\cline { 3 - 5 } & & Mean \pm SD & Mean \pm SD & 0.579 \\
\hline Anxiety trait & 80 & $51.02 \pm 7.17$ & $50.62 \pm 6.87$ & 0.856 \\
\hline Anxiety state & 80 & $51.20 \pm 8.92$ & $51.04 \pm 8.99$ & 0.677 \\
\hline Anxiety total & 160 & $102.22 \pm 13.70$ & $101.65 \pm 12.45$ & 0.700 \\
\hline Stress & 40 & $20.64 \pm 5.82$ & $20.86 \pm 4.23$ & \\
\hline
\end{tabular}


Table (8): The relationship between anxiety and stress with OSCE attributes

\begin{tabular}{|c|c|c|c|c|c|c|c|c|}
\hline \multirow{2}{*}{ OSCE attributes } & \multicolumn{2}{|c|}{ Anxiety trait } & \multicolumn{2}{|c|}{ Anxiety state } & \multicolumn{2}{|c|}{ Anxiety total } & \multicolumn{2}{|c|}{ Stress } \\
\hline & r-value & P-value & r-value & P-value & r-value & P-value & r-value & P-value \\
\hline Evaluation of OSCE & 0.029 & 0.540 & -0.3230 & $0.000 *$ & -0.201 & $0.000 *$ & -0.136 & $0.004 *$ \\
\hline $\begin{array}{l}\text { Quality of } \\
\text { performance }\end{array}$ & 0.006 & 0.892 & -0.2000 & $0.000 *$ & -0.131 & $0.005 *$ & -0.226 & $0.000 *$ \\
\hline $\begin{array}{lll}\text { Students' perception of } \\
\text { validity and reliability }\end{array}$ & 0.034 & 0.477 & -0.1740 & $0.000^{*}$ & -0.099 & $0.035^{*}$ & -0.123 & $0.009 *$ \\
\hline Total score of OSCE & 0.024 & 0.609 & -0.2820 & $0.000 *$ & -0.176 & $0.000 *$ & -0.194 & $0.000 *$ \\
\hline
\end{tabular}

Table (1): presents personal characteristics of studied students. Around two-thirds of the first and fourth year, nursing students came from rural areas $(60 \%$ and $64 \%$, respectively).While The mean age of the first and fourth year nursing students was (17.94 \pm 0.99 and $21.04 \pm 0.78)$, respectively.

Figure (1): shows percentage distribution of students according to their academic level with higher percentage of students in the first year compared to fourth year students $(69.2 \%$ and $30.8 \%$, respectively).

Table (2): demonstrates mean scores of evaluation of OSCE. There are significant differences regarding the items of the exam was fair, wide range of area covered, needed more time at stations, OSCE was less stressful than another exam, allowed students to compensate in some areas, highlighted of weakness, the time for each question was adequate, the questions asked were of appropriate level. (p- values: $0.038,0.032,0.018,0.003,0.027,0.000,0.043$, 0.003 , respectively) with a significant difference of total mean score between first and fourth year nursing students $(\mathrm{P}$ - value $<0.01)$.

Table (3): shows mean scores of quality of OSCE performance with significant difference between first and fourth year nursing students as regards fully aware of the nature of the exam, time at each station was adequate and exam was intimidating ( $\mathrm{P}$ - values: $0.040,0.18$ and 0.025 , respectively).

Table (4): illustrates mean scores of students' perception of validity and reliability with a significant difference between first and fourth year nursing students regarding only the item of personality and social relations will not affect OSCE scores as well as the total mean score (P-value 0.038 and 0.031 , respectively).

Figure (2): indicates the perception of the first and fourth year nursing students for OSCE attributes. The higher mean score was for a total score of OSCE followed by evaluation of OSCE for both first and fourth nursing students.

Table (5): illustrates the stress mean score during OSCE. There was no significant difference between first and fourth year nursing students regarding all statements of stress except feeling angry because of things that are out of control in the last month $(3.12 \pm$ 1.49 Vs. $3.56 \pm 1.26$, respectively P- Value 0.002 ).

Table (6): demonstrates percentage distribution of the anxiety levels among studied students. The majority of the nursing students experienced a moderate level of anxiety with no significant differences between the first and fourth year nursing students $(84.6 \%$ and $89.2 \%$ for both first and fourth year nursing students, respectively.

Table (7): illustrates mean score of the anxiety and stress between first and fourth nursing students during OSCE. No significant differences were found between first and fourth year nursing students as regards neither anxiety nor stress.

Table (8): shows the relation between anxiety and stress with OSCE attributes. There was a significant negative correlation between anxiety state, total anxiety, and stress with evaluation of OSCE. (r- test: - 0.03230, - 0.201, - 0.136, respectively. P- values: $0.000,0.000$ and 0.004 , respectively). Also, there was a significant negative correlation between anxiety state, total anxiety, and stress with both qualities of OSCE performance, students' perception of validity and reliability and a total score of OSCE.

\section{Discussion}

The objective structured clinical skills examination (OSCE) has over the years emerged as a method of evaluating clinical skills in most medical and allied professions. It is an effective assessment strategy for assessing clinical skills (Alinier et al., 2009, Watson et al., 2002) and for highlighting curriculum problem areas (Rushforth, 2007). Their popularity has increased among nurse teaching staff over the last decade (Annabel, 2007)

The study results suggested that OSCE is a useful and acceptable tool for evaluating students' performance of clinical skills. Most students viewed OSCE as a fair assessment tool which covered a broad area of knowledge, and allowed them to compensate in some areas but needed more time at stations. This result is in accordance with Pierre et al., (2004) who reported favorable responses by students concerning 
transparency and fairness of examination process. The fairness of OSCE was also reported by ElNemer \& Kandeel, (2009) and another study done by Duffield \& Spencer, (2002).

This result is also in agreement with Eswi et al., (2013) \& Ali et al., (2012) \& Sleem et al., (2012) who reported that most students viewed OSCE as a fair assessment tool, covered a wide range of knowledge and allowed them to compensate in some areas and half of the studied students' agreed that the stations need more time. Moreover, Mater et al., (2014) \& Abdel- Nasser et al., (2012) added that OSCE is a fair examination and around half of them felt that it maximizes the chance of excellence. In the same line Mohmoud \& Mostafa (2011) \& Alinier et al., (2009) reported that fairness of OSCE. In a study conducted to assess validity, reliability and feasibility of team OSCE the majority of students felt that they had been marked fairly.

The current study also found that the items of OSCE high lightened weakness and the time for each question was adequate and questions were of the appropriate level. These results are in accordance with Eswi et al., (2013) who concluded that the majority of students reported that the time of each question was adequate. However, the low mean score was reported by both first and fourth year nursing students regarding that OSCE cover a wide range of clinical skills which highlighted a gap in the application of OSCE in the form of the increased bulk of theoretical knowledge being tested at the expense of clinical skills. This may be related to the increased number of students with decreased number of teaching staff in addition to decreased equipment which leads to the increase in the number of photo stations than communication and procedure stations. This is a problem not only in Assiut but also El Darir et al., (2010) reported in their study that using OSCE was described to have certain obstacles such as shortage of staff members who can implement OSCE. The present study found that students were fully aware of the nature of the exam and exam was intimidating. This result is in accordance with Shitu \& Girma, (2008). Concerns about intimidation of the exam have been reported in the literature (Russell et al., 2004 \& Imani \& Hosseini, 2005). Also Pierre et al., 2004, Delavar et al., 2013 \& Mater et al., (2014) found that several students felt that the examination was stressful and intimidating. Moreover, Bayoumy et al., (2012) found that the majority of the studied students agreed that they were fully aware of the exam's nature. However, Eswi et., (2013) found that the minority reported that OSCE is intimidating.

The current study indicated a significant result regarding that personality and social relations will not affect OSCE scores. This is in accordance with EI Nemer \& Kandeel (2009) who found that OSCE was not affected by personality and social relations. The same result was reported by Eswi et al., (2013). The present study failed to find a significant difference between first and fourth year nursing students regarding neither stress nor anxiety, although the majority of them experience moderate anxiety during the exam.

This study didn't find any significance between the first and fourth year nursing students regarding stress mean score. This is because OSCE exam was stressful situations as many other types of the exam as well as part of the routine work in the faculty of Nursing Assiut University is the good preparation of students before the beginning of OSCE exam and some departments do the clinical rotation exam as OSCE in the lab. This is in accordance with Rentschler et al., (2007) who found OSCE was a favorable experience. Moreover, Eswi et al., (2013) reported the same result. However, El- Nemer and Kandeel, (2009) found that a number of students felt that OSCE was not less stressful than other methods of examination and some of them considered it, even more, stressful.

This study found a significant negative correlation between the evaluation of OSCE, quality of OSCE performance, students' perception of validity and reliability and a total score of OSCE with anxiety state, total anxiety, and stress. This finding can be interpreted with the fact that the increase in anxiety level leads to decrease in concentration state during the exam and thereby affect students' perception of all attributes of OSCE.

\section{Conclusion}

The nursing students' perception about OSCE was favorable regarding the examination objectivity, covers a wide area of knowledge, needs more time at the station but they perceived that OSCE didn't cover a wide range of clinical skills. No significant difference was found between $1^{\text {st }}$ and $4^{\text {th }}$ year nursing students regarding stress and anxiety.

\section{Recommendation}

\section{based on this study, it recommends that}

- On a closer look, there are gaps with respect to objectivity, validity and reliability of this assessment, especially in settings with poor resources and increased number of students with decreased number of staff. It requires more efforts and budget to design OSCE stations that need to measure the essential professional competences which including the ability to work in a team, 
professional ethical behavior and ability to reflect on own self-appraisal.

- Steering committee in the faculty should be responsible for OSCE exam in all the departments of the faculty.

\section{References}

1. Ali G., Mehdi A., \& Ali H., (2012): Objective Structured Clinical Examination (OSCE) as an assessment tool for clinical skills in Sohag University: Nursing Students' perspective. Journal of Environmental Studies (JES) 8: 5969.

2. Alinier G., (2009): Nursing student's and lecturer's perspectives of objective structured clinical examination incorporating simulations. Nurse Education Today, 23 (6): 419- 26

3. Annabel, J., ((2007): Students' perceptions of the OSCE: a valid assessment tool? British Journal of Midwifery, 15(1).

4. Austin Z., O’Byrne C., Pugsley J., Munoz L., (2003): Development and validation processes for an objective structured clinical examination (OSCE) for entry- to practice certification in pharmacy: The Canadian experience. American Journal of Pharmaceutical Educations, 67(3): 1-8

5. Bartfay, W., Rombough, R., Howse, E., \& LeBlanc, R., (2004): The OSCE approach in nursing education: Objective structured clinical examinations can be effective vehicles for nursing education and practice by promoting the mastery of clinical skills and decision-making in controlled and safe learning environments. The Canadian Nurse, 100(3): 18-25.

6. Bayoumy H., \& Yousri H., (2012): Objective Structured Clinical Examination (OSCE )Based assessment in Nursing :students' and clinical instructors' perception, Journal of American Science ,8(9): 523540 .

7. Benner, P., Sutphen, M., Leonard, V. \& Day, L., (2010): Educating nurses: A call for radical transformation. San Francisco, CA: Jossey-Bass.

8. Benseñor, E., (2004): How to evaluate the acquisition of clinical skills at medical school: A tough question. Sao Paulo Medical Journal, 122(1):12-7.

9. Cohen, S., Kamarck, T., \& Mermelstein, R., (1983). A global measure of perceived stress. Journal of Health and Social Behavior, 24, 38696.

10. Delavar, M., Salmalian, M., Faramarzi, H. Pasha, M., Nikpour \& F., Ledari, (2013): Using Objective Structured Clinical Examinations in undergraduate midwifery students. Journal of Medicine and Life, 6: 76-9.
11. Duffield K., \& Spencer J., (2002) : A survey of medical students' views about the purposes and fairness of assessment. Med Educ 36:879-886. PubMed Abstract | Publisher Full Text.

12. El - Beheary A., (1998): State -trait anxiety scale for children. Second edition - Dar- El Maraaf.

13. Eldarir S., El Sebaae H., El Feky H., et al., (2010): An introduction of OSCE versus traditional method in nursing education: faculty capacity building \& students' perspectives. Journal of American Science; 6 (12): 1002-14.

14. El-Nemer, A., Kandeel N., (2009): Using OSCE as an Assessment Tool for Clinical Skills: Nursing Students' Feedback. Australian Journal of Basic and Applied Sciences,3(3): 2465-72.

15. Eswi A., Badawy A., \&Staliabe H., (2013): OSCE in Maternity and Community Health Nursing : Saudi Nursing student's Perspective .American Journal of Research communication;1 (3) :143-162 .

16. Imani M., Hosseini M., (2005): Is OSCE successful in pediatrics? Journal of Medical Education winter,6(2):153-8.

17. Ireland: A utilization-focused evaluation. Nurse Education Today, 26: 115-22.

18. Khattab, A., \& Rawlings, B., (2001): Assessing nurse practitioner students using a modified objective structured clinical examination (OSCE). Nurse Education Today 21, 541-50.

19. Mahmoud G., Mostafa. M., (2011): The Egyptian Nursing Student's Perceptive view about an Objective Structured Clinical Examination (OSCE). Journal of American Science, 7(4):730-8

20. Major, D., (2005). OSCEs - seven years on the bandwagon: the progress of an objective structured clinical evaluation programme. Nurse Education Today, 25 (6): 442-54.

21. Mater E., Ahmed E., El Sayed A., El Shaikh MA and Farag M K. (2014): The impact of the objective structured clinical examination approach for clinical evaluation skills on the student's performance in nursing college. World Journal of Medial Sciences .11 (4): 609- 13.

22. Miller, J., (2009): Competency-based training: objective structured clinical exercises (OSCE) in family therapy. Journal of Marital and Family Therapy, 53: 23-34.

23. Mitchell, M., Henderson, A., Groves, M., Dalton, M., \& Nulty, D., (2009): The objective structured clinical examination (OSCE): Optimizing its value in theobjective structured clinical examination (OSCE). Nurse Educ. Today 20, 541-50. 
24. Panzarella, K., \& Manyon, A., (2007): A Model for Integrated Assessment of Clinical Competence. Journal of Allied Health, 36:157164.

25. Pierre, R., Wierenga, A., Barton M., Brandy, M., Chrisite, C., (2004) : Student evaluation of an OSCE in pediatrics at the University of the West Indies, Jamaica. BMC Medical Education 4: 22

26. Rentschler, D., Eaton, J., Cappiello, S., McNally, S., McNally \& P., McWilliam, (2007): Evaluation of undergraduate's students using objective structured clinical evaluation. Research Briefs,.46(3): 135-9.

27. Rosemarie G., (2002): web services choreography interface (WSCI) specifications related to the public Gamelean (developer.com) retrieved on 20 July 2008 , from http: //www.developer.com/jawa/article Php/1376901.

28. Rushforth, H., (2007): Objective Structured Clinical Examination (OSCE): review of literature and implications for nursing education. Nurse Education Today; 27 (5): 481-90.

29. Russell B., Andrea W., Michelle B., Michael B., \& Celia D., (2004): Student evaluation of an OSCE in paediatrics at the University of the west Indies, Jamaica. BMC Med Educ,; 4: 22.

30. Shitu B., Grima T., (2008): Objective structured clinical examination (OSCE): Examinee's perception at departmentof pediatrics and child health, Jimma University. Ethiop J Health Sci, 18 (2): 47-52.

31. Sleem W., El- Shaer A., El Atroush H., (2012): Does implementing for an objective structure clinical examination make a difference?. Medical Journal of Cairo University; 80 (2): 239- 47.

32. Spielberger, C., Edwards, C., Lushene, R., Montuori, J., \& Platzek, D., (1973): Preliminary manual for the State-Trait Anxiety Inventory for Children. Palo Alto, CA: Consulting Psychologists

33. Walsh, M., Bailey, P., \& Koren, I., (2009): Objective structured clinical evaluation of clinical competence: An integrative review. Journal of Advanced Nursing, 65 (8): 1584-95.

34. Ward, H., \& Barratt, J., (2005): Assessment of nurse practitioner advanced clinical practice skills: using the objective structured clinical examination (OSCE): Helen Ward and Julian Barratt examine how OSCEs can be developed to ensure a robust assessment of clinical competence. Primary Health Care, 15 (10): 37 41.

35. Watson, R., Stimpson, A., Topping, A., \& Porock, D., (2002): Clinical competence assessment in nursing: a systematic review of the literature. Journal of Advanced Nursing, 39 (5): 421-31.

36. Wessel, J., Williams, R., Finch, E., \& Gemus, M., (2003). Reliability and Validity of an Objective Structured Clinical Examination for Physical Therapy Students. Journal of Allied Health, 32(4): $266-71$. 